\title{
МОДЕЛЮВАННЯ ТЕХНОЛОГІЧНОГО ПРОЦЕСУ ВИДАВЛЮВАННЯ ЗАГОТОВОК КОМПРЕСОРНИХ ЛОПАТОК
}

Лопатки авіаційних двигунів є найбільш масовими та навантаженими деталями. До них висуваються особливі вимоги за структурою матеріалу, його хімічним складом, механічним властивостям, геометричним розмірам, а особливо виключенням дефектів при виготовленні [1].

При виготовленні заготовок компресорних лопаток методом видавлювання спостерігаються наступні дефекти: виникнення заковів, прес-утяжини та несуцільності матеріалу, які надалі можуть потрапляти в тіло лопатки та призводити до зниження характеристик міцності. На виникнення дефектів впливають технологічні параметри виготовлення заготовки лопатки: швидкість деформації, температура, тертя на контактній поверхні та геометричні розміри деталі [2].

Для забезпечення конкурентоспроможності необхідний комплексний підхід в проектуванні процесу виробництва. Сучасні системи моделювання дозволяють значно скоротити витрати та час розробки нового оснащення за рахунок віртуального моделювання процесу штампування, без виготовлення оснащення та завантаження ковальсько-пресового обладнання.

Метою даної роботи є чисельне моделювання процесу видавлювання заготовок компресорних лопаток авіаційних двигунів із вирішенням задач пластичного деформування, порівняння результатів моделювання із фактичними результатами видавлювання.

В якості системи моделювання процесів використовується програма QForm 2D/3D, за допомогою якої можна варіювати різними параметрами процесу деформування. Моделювання процесу видавлювання заготовок компресорних лопаток складається із наступних етапів:

- створення 3D-моделі видавленої заготовки компресорної лопатки із дотриманням всіх вимог, що висуваються до геометричних розмірів деталі. Створення 3D-моделей штампового оснащення та заготовки під видавлювання;

- моделювання процесу видавлювання із вихідними даними реального процесу за допомогою програмного забезпечення QForm 2D/3D;

- проведення порівняльного аналізу результатів моделювання із фактичними результатами видавлювання заготовок компресорних лопаток [3-5].

Процес видавлювання заготовки компресорної лопатки моделювався за фактичними розмірами лопатки та штампового оснащення. На першому етапі моделювання було створено 3D-модель видавленої заготовки компресорної лопатки (рис. 1).

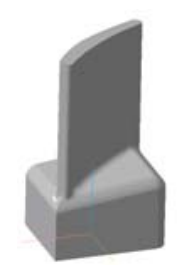

Рис. 1. 3D-модель видавленої заготовки компресорної лопатки

Після цього за формою іï профілю з урахуванням температурного розширення створено моделі штампового оснащення - пуансону і матриці, яка складається із двох половин та має скошене дно. Для того щоб в процесі видавлювання забезпечити плавний плин металу, збільшити стійкість інструменту та зменшити концентратори напружень, в матриці місце переходу від вхідної частини до порожнини, де формується перо лопатки, виконано із максимальними радіусами заокруглень (рис. 2). 


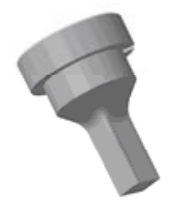

a

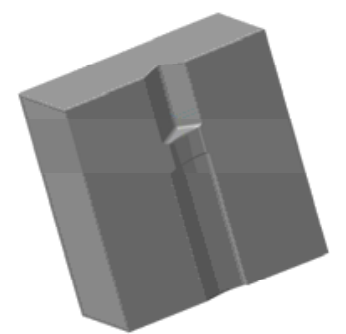

6

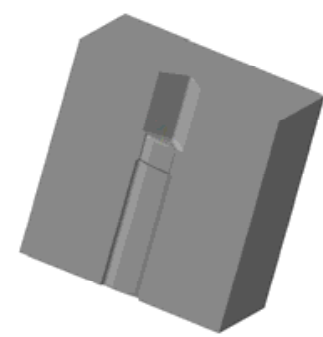

B

Рис. 2. 3D-модель штампового оснащення:

a - пуансон; б - ліва півматриця; в - права півматриця

Для можливості подальшого моделювання в QForm було з'єднано дві половини штампу. Після цього в додатку QShape на інструменті та заготовці було нанесено сітку кінцевих елементів. (рис. 3).

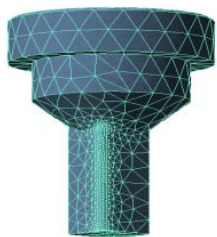

a

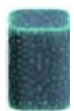

б

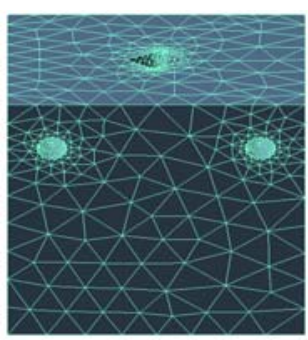

B

Рис. 3. Нанесення сітки методом кінцевих елементів:

a - пуансон; б - заготовка для видавлювання; в - матриця у зборі

При моделюванні процесу видавлювання заготовки компресорної лопатки було використано вихідні умови, які використовуються в реальному виробництві. Процес видавлювання заготовки розглядали як об'ємну задачу. В якості обладнання було обрано модель механічного пресу зусиллям 6,3 МН.

Деформуючий інструмент вважався абсолютно жорстким. Задавалася температура підігрівання робочого інструменту згідно із діючою технологією до $300^{\circ} \mathrm{C}$.

За модель матеріалу заготовки було обрано титановий сплав ВТ6. Розрахунок проводився із застосуванням графітової змазки із коефіцієнтом тертя $\mu=0,3$. Температура нагрівання заготовки дорівнює $900{ }^{\circ} \mathrm{C}$.

В результаті комп’ютерного моделювання процесу видавлювання заготовки компресорної лопатки характерного розміру 27 мм отримано дані щодо заповнення гравюри штампу та зонам затрудненого плину металу із наявністю дефектів. (рис. 4).

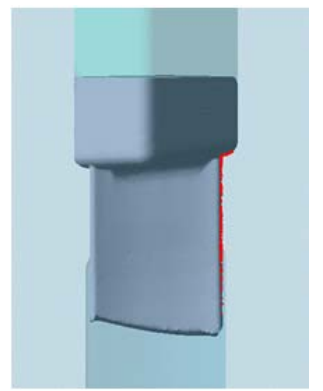

Рис. 4. Змодельована в QForm заготовка компресорної лопатки, отримана методом видавлювання

На рис. 5 представлено розподіл опору деформуванню, а на рис. 6 - швидкостей плину металу, на основі аналізу яких зразок можна умовно розділити на чотири зони (рис. 6, в). 


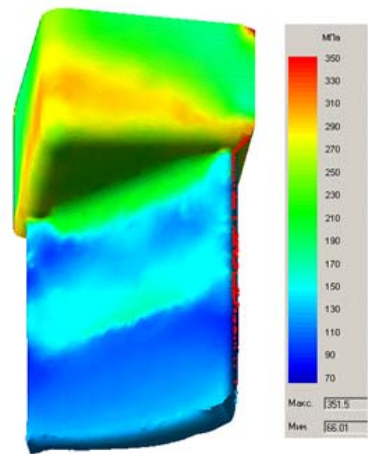

a

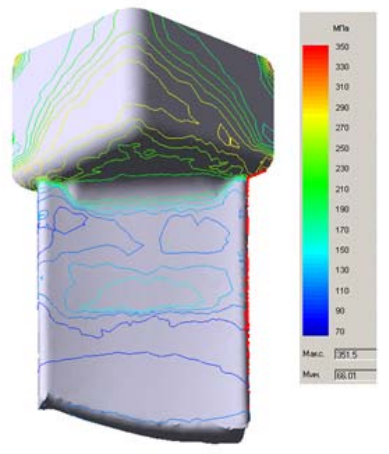

6

Рис. 5. Розподіл опору деформуванню на поверхні:

а - ізолінії опору деформуванню; б - ізолінії вектору опору деформуванню вздовж осі пера лопатки

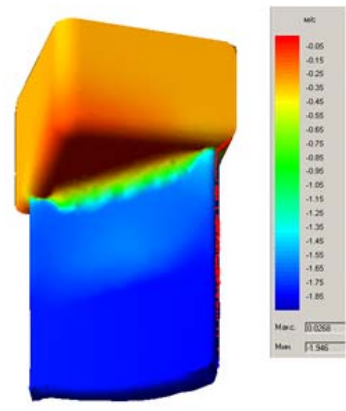

$\mathrm{a}$

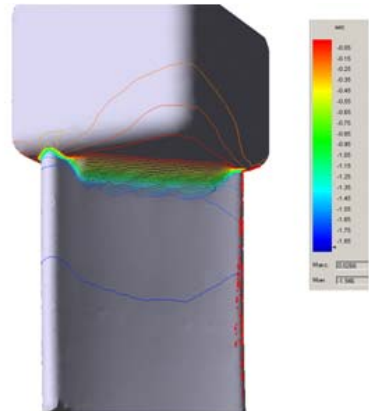

6

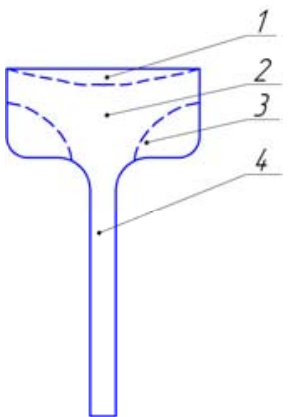

B

Рис. 6. Розподіл швидкостей плину металу на поверхні:

a - ізолінії вектору швидкостей; б - ізолінії вектору швидкостей матеріальних часток вздовж осі пера лопатки; в - характерні зони плину металу

На зразку 1 та 3 зони є зонами затрудненого плину металу, так як у зоні 1 відбувається контакт металу заготовки із пуансоном. В 4 зоні спостерігається застій металу через конструктивні особливості деталі. Інтенсивний плин металу спостерігається в зоні 2. Метал тече в порожнину матриці, де відбувається формування пера лопатки. Тут спостерігається 4 зона сталого плину металу.

Розподіл середніх напружень заготовки в процесі деформування показано на рис. 7.

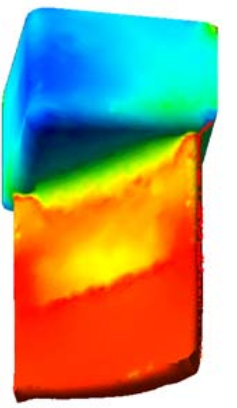

$\mathrm{a}$

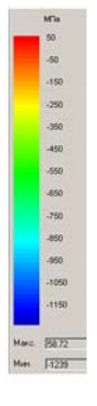

Рис. 7. Розподіл середніх напружень:

a - ізолінії середніх напружень; б - ізолінії вектору середніх напружень вздовж осі пера лопатки

Аналіз показує, що напруження в ході деформації змінюють свій знак. У прес-залишку, де пуансон діє на заготовку спостерігається інтенсивне напруження стиску, яке по мірі просування до пера лопатки зменшується. У сформованому пері заготовки компресорної лопатки спостерігається поступове зростання довжини пера, яке супроводжується напруженням розтягання. 
Залежність зусилля процесу видавлювання заготовки компресорної лопатки від часу проведення операції представлено на рис. 8.

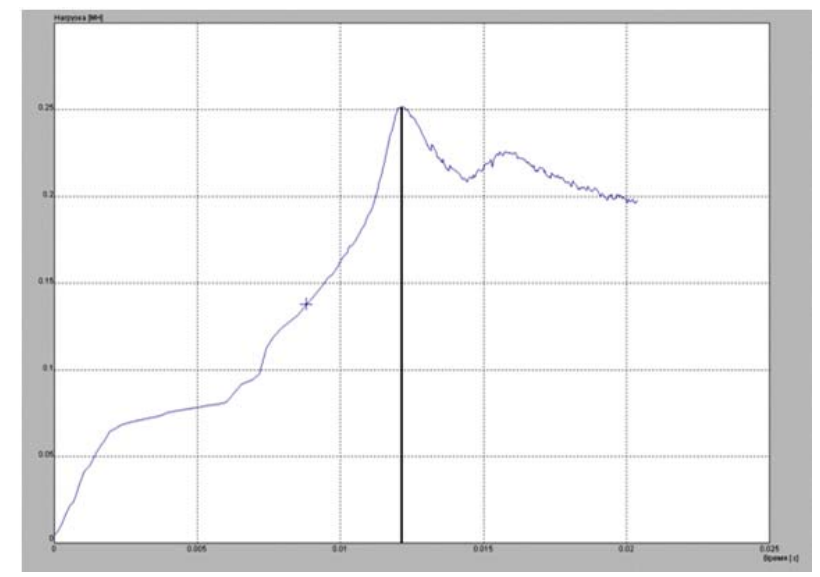

Рис. 8. Графік залежності зусилля пресування від часу

Зусилля зростає поступово по мірі заповнення металом заготовки порожнини матриці та формування пера заготовки компресорної лопатки. На першому етапі відбувається осаджування плющеної заготовки. Далі заготовка входить у контакт зі стінками матриці, зростає сила тертя i, внаслідок цього, зусилля. Максимальне зусилля на цьому етапі становить 0,253 МН. Після цього зусилля дещо знижується.

Для перевірки результатів комп'ютерного моделювання процесу видавлювання заготовок компресорних лопаток за допомогою програмного пакету QForm було проведено експериментальне дослідження на установці для серійного виробництва. Отримано серію заготовок із поступовим збільшенням довжини пера лопатки. (рис. 9).

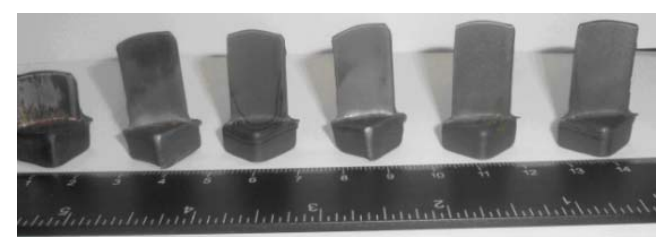

Рис. 9. Заготовки компресорних лопаток, отримані із поступовим збільшенням довжини пера

Отримані заготовки свідчать про повне заповнення гравюри штампу та відсутність заковів і тріщин на тілі деталі, при цьому контур деталі відповідає розрахунковому.

Перед видавлюванням на бічну поверхню заготовки було нанесено горизонтальні лінії (рис. 10) для того, щоб оцінити характер плину металу. На отриманій заготовці чітко видно характерні зони застою металу, такі самі, як і при комп'ютерному моделюванні (рис. 11).
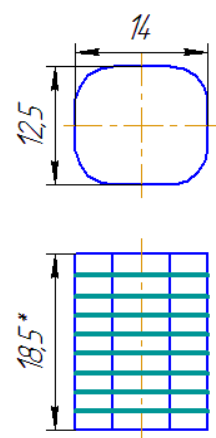

Рис. 10. Схема заготовки під видавлювання

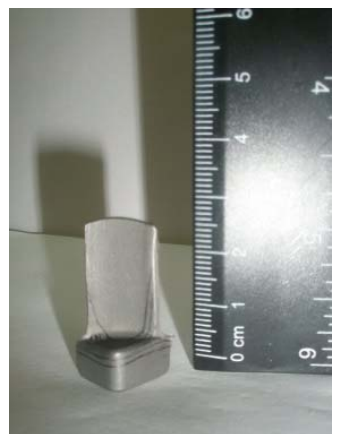

Рис. 11. Видавлена компресорної лопатки заготовка 


\section{ВИСНОВКИ}

Проведено якісне порівняння отриманих поковок із результатами комп'ютерного моделювання процесу видавлювання.

Комп’ютерне моделювання процесу видавлювання заготовки компресорної лопатки показало відповідність форми видавленої заготовки, яку отримано розрахунковим шляхом, зовнішній формі реальної заготовки, заповнення порожнини матриці, а також місця виникнення дефектів. Показано користь використання застосованих технологій для моделювання процесу деформації та виготовлення штампового оснащення.

\section{СПИСОК ВИКОРИСТАНОЇ ЛІТЕРАТУРИ}

1. Точная горячая штамповка деталей ГТД / [Богуслаев В. А., Кресанов Ю. С., Качан А. Я. и др.] ; под ред. В. А. Богуслаева. - Запорожье, 2017. - 563 с.

2. Технологічна механіка забезпечення міцності та якості деталей пластичним деформуванням / [Тітов В. А., Злочевська Н. К., Качан О. Я. та ін.]. - Київ : КВІЦ, 2016. - 176 с.

3. Кабаков О. Г. Компьютерное моделирование технологического прочесса горячей штамповки деталей типа “Лопатка ГТД” с помощзью программного пакета QForm 2D/3D [Электронный ресурс] / Кабаков О. Г., Кирносов В. И., Федотов Д. С. // Повышение эффективности процессов изготовления ответственных деталей авиа- и двигателестроения штамповкой и литьем. Разработка, моделирование и оптимизация технологий с использованием программ QForm и ProCAST: Электронный сб. тр. семинара (28 сентября 2010 г.). - М., 2010. - Режим достуna: http://seminar.qform3d.ru/?go=articles 2010\&id=22.

4. Гладков Ю. А. Моделирование технологических прочессов штамповки при решении задач авиаи двигателестроения / Ю. А. Гладков, П. С. Мордвиниев // КШП ОМД. - 2012. - № 15. - С. $38-47$.

5. Мамаев М. В. Исследование прочесса выдавливания и его технологических параметров при изготовлении заготовок лопаток ГТД [Электронный ресурс] // Повышение эффективности производства деталей авиадвигателей с применением программы QForm: Электронный сб. тр. Семинара (24 сентября 2009 г.). - М., 2009. - Режим доступа: http://seminar.qform 3 d.ru/db files/articles/28/presentation.zip.

\section{REFERENCES}

1. Tochnaja gorjachaja shtampovka detalej GTD / [Boguslaev V. A., Kresanov Ju. S., Kachan A. Ja. i dr.] ; pod red. V. A. Boguslaeva. - Zaporozh'e, 2017. - 563 s.

2. Tehnologichna mehanika zabezpechennja micnosti ta jakosti detalej plastychnym deformuvannjam / [Titov V. A., Zlochevs'ka N. K., Kachan O. Ja. ta in.]. - Kyi'v : KVIC, 2016. - 176 s.

3. Kabakov O. G. Komp'juternoe modelirovanie tehnologicheskogo processa gorjachej shtampovki detalej tipa “Lopatka GTD” s pomoshh'ju programmnogo paketa QForm 2D/3D [Jelektronnyj resurs] / Kabakov O. G., Kirnosov V. I., Fedotov D. S. // Povyshenie jeffektivnosti processov izgotovlenija otvetstvennyh detalej avia- $i$ dvigatelestroenija shtampovkoj $i$ lit'em. Razrabotka, modelirovanie $i$ optimizacija tehnologij s ispol'zovaniem programm QForm i ProCAST: Jelektronnyj sb. tr. ceminara (28 sentjabrja 2010 g.). - M., 2010. - Rezhim dostupa: http://seminar.qform3d.ru/ $? g o=$ articles_2010\&id=22.

4. Gladkov Ju. A. Modelirovanie tehnologicheskih processov shtampovki pri reshenii zadach avia- $i$ dvigatelestroenija / Ju. A. Gladkov, P. S. Mordvincev // KShP OMD. - 2012. - № 15. - S. 38-47.

5. Mamaev M. V. Issledovanie processa vydavlivanija i ego tehnologicheskih parametrov pri izgotovlenii zagotovok lopatok GTD [Jelektronnyj resurs] // Povyshenie jeffektivnosti proizvodstva detalej aviadvigatelej s primeneniem programmy QForm: Jelektronnyj sb. tr. Seminara (24 sentjabrja 2009 g.). - M., 2009. - Rezhim dostupa: http://seminar.qform 3 d.ru/db_files/articles/28/presentation.zir.

Тітов В. А. - д-р техн. наук, проф. НТУУ «КПІ ім. І. Сікорського»; Бень А. М. - ст. викл. ЗНТУ.

НТУУ «КПІ ім. І. Сікорського»- Національний технічний університет України «Київський політехнічний інститут імені Ігоря Сікорського», м. Київ.

ЗНТУ - Запорізький національний технічний університет, м. Запоріжжя.

E-mail: vat.kpi@gmail.com; benanna@,zntu.edu.ua 